\title{
SOCIAL DIALOGUE AS THE ESSENCE OF VIRTUAL ORGANIZATIONS
}

\begin{abstract}
The organization's operation in a virtual environment is based on a specific form of communication - social dialogue. The purpose of the article is to describe the phenomenon of social dialogue and its elements: (1) the sender/producer, (2) recipient/customer, and (3) hypertextuality of the environment in which the process takes place. The adopted research method is a qualitative analysis supported by the technique of real-defining definition. Results of this work imply that text in the new media is not only thought of as a creator of meanings, but to extend this understanding to all cultural creations. This means that the fundamental change concerns the perception of the text as a dynamic mechanism of producing meanings, and not the static reception of the record as before. These implications is particularly important for the study of cultural products such as behavioral patterns, for example. Thus, understanding the mechanisms of technical functioning and the human factor in this world can give real profits. Lack of humility towards this medium and disproportionate losses as to the cost of their own ignorance.
\end{abstract}

Keywords: virtual reality, sender / virtual producer, recipient / virtual client, hypertextuality.

\section{INTRODUCTION}

Communication in the network is in the form of social dialogue. This concept is most often referred to public communication, usually institutional. Dialogue in this sense has a broader meaning, as it includes not only conversation, but all activities that are to lead and bring about agreement. In other words, it is a social process based on partnership and mutual subjective treatment. Understanding the mechanisms of technical functioning and the human factor in this world can give real profits. Only the ability to understand the behavior of Internet users in a communication system that allows you to track changes between the sender and recipient

Undertaking the effort to define virtual reality is not so much a methodological issue but, above all, a cognitive condition that allows us to understand the essence of the virtual environment, which some researchers call the "pseudo-environment". In the literature that is often found, this term is used in various aspects and depending on the need. There is still a lack of common and scientific agreement that could be normative in this respect. However, the emergence of new media and their consolidation in the life of modern society prompts

\footnotetext{
${ }^{1}$ Professor Justyna Lipińska, PhD, The Faculty of Management and Command, The War Studies University, 1. gen. A. Chruściela „Montera” 103, 00-910 Warszawa-Rembertów; e-mail: j.lipinska@akademia.mil.pl. ORCID: 0000-0001-8233-6971.
} 
each researcher to respond to themselves as well as others, as he understands the concept of virtual reality.

Getting to know the problems of the Internet, its tool aspect having a basic impact on the emergence of the concept of virtual reality, as well as the psychological aspect, one can notice a multitude of terms used interchangeably with the one I have adopted, which is the result of various terminology approaches. Therefore, at the beginning, other terms will be quoted in chronological order, which as a result of technological and humanistic development have become the basis for creating the term "virtual reality".

At the beginning of the development of the Internet, a very popular term was: "artificial reality" proposed by Myron Krueger in the book of the same title, "virtual environments" (Krueger, 1991) used by specialists from NASA and MIT, "virtual worlds" used by researchers from the University of North Carolina and the University of Washington. Equally common and today the term is "cyberspace" used for the first time in William Gibson's Neuromancer cyberpunk novel. With this concept it is worth stopping for a moment, because it is most often used as a synonym of virtual reality. Michael Heim believes "that cyberspace refers to information space, to the fusion of digital information and human perception" (Hiem, 1993). More specifically, cyberspace defines Elizabeth Reid when he writes

"Nominally, all data paths can be called cyberspace. Telephone lines, optical fibers and satellite connections are part of the global cyberspace, which is the Internet. This cyberspace becomes more tangible and takes the form of virtual reality where users of these networks can enter it with their imagination" (Reid, 1994).

As it results from this, cyberspace is not a medium, but rather an area, as Piotr Sitarski notes "in some respects analogous to geographical space" (Sitarski, 2002). Therefore, virtual reality is a different concept from cyberspace, because only it can be a space accessible to human sensations, and cyberspace can only be a physical place received in the real world.

The terminological distinctions cited above, which are synonyms of the concept of "virtual reality", which are found in literature, are not infrequently mixed and are inconsistently used by researchers or novelists, which introduces a large methodological confusion. The modern concept of "virtual reality" itself has two approaches. The first focuses on technical aspects, the second on psychological ones. Supporters of the technical approach focus on determining the minimum set of instruments necessary to create a virtual world. This approach, Jonathan Steuer notes, has several disadvantages. First of all, the selection of tools (instruments) is limited and arbitrary due to the possessed technology. Secondly, he does not focus on a living participant in the relationship with the tool, but only on the apparatus. Thirdly, it cannot distinguish between different virtual systems (Sitarski, 2002). The second approach mentioned is based on a psychic phenomenon where the participant experiences the illusion of being in another world. Proponents of this approach completely focus new experiences and they are the only determinant of the existence of another reality. They do not pay attention to the technical aspect, which carries a very serious objection to this approach. Namely, since the condition of the existence of virtual reality is "the difference of states of consciousness", what can this concept be used at the time of "achieving other sensations" received artificially, e.g. through chemicals or 
meditative practices. Errors in both approaches have been noticed and taken into account by Steve Austakalnis and David Blanter in their book "The Sillicone Mirage" in 1992. They define virtual reality "as the way people interact with computers and extremely complex data, as well as picture and manipulate it". Going further, Frank Biocca defines virtual reality as a "class of computer-controlled, multi-sensory communication techniques" (Biocca, 1992). And so for the needs of this study the following definition was adopted. According to which virtual reality is a property common to all types of virtuality that are deeply embedded in technology and at the same time go beyond it. Interactivity is the condition of this offense in the communicative dimension, as mentioned by Frank Biocca. According to Ryszard W. Kluszczyński, in the book Aesthetic spaces of the present day in the chapter "Interactivity - the property of reception or a new quality of art / culture" - "interactivity is a new quality of holistically understood culture and a new quality of art" (Tucker, 1989). The thing with interactivity is similar to virtual reality - there are no precise definitions of this phenomenon. He was studied by such great researchers as Rudy Bretz and Andrew Lippman (they proposed a definition focusing on machine technology without taking into account the human element), Ronald Rice (defining interactivity as the real freedom of human choice) and finally Richard Tucker (understanding interactivity as systems in which the output from relays can be defined by user actions). R. Tucker and R. Kluszczyński unanimously note, however, that interactivity must be related to communication or even the entire communication system in virtual reality - "interactivity is combined with communication and the resulting interaction between human and electronic machine (in a larger or smaller) degree) artificial intelligence" (Kluszczyński, 1996).

The perception of virtual reality as a computer communication technique, which can be determined by interactivity in this environment, allows you to observe the behavior of Internet users in a communication system that allows you to track changes between the sender and the recipient. Applying a simple communication system proposed by Warren Weaver and Claude Shannon to this situation may be surprising, because as I will show in the further part of the dissertation, this approach is quite incorrect and burdened with a methodological error, however, at this point, it will allow you to understand the essential elements of virtual communication that are immutable for all communication systems.

\section{SENDER / PRODUCER OF VIRTUAL REALITY}

The broadcaster's issues are widely considered in the context of traditional media, while in the context of electronic media, there are not many items in this field on the publishing market. When looking at the issue of the authorship of a traditional work, two approaches come from literary studies: traditional - regarding the author of the work and its recipient, and social - involving the activities of all intermediary instances. Pierre Schaeffer "calls them the dominant of expression and dominant, respectively", Robert Escarpit "writes about the process and apparatus" (Sitarski, 2002, za Lalewicz, 1985). Thus, the sender's problem has two areas in which it should be considered. One of them is the traditional sphere of the author of the work, the other the social sphere of the collective apparatus by means of which the work was produced. This is particularly evident in book or film productions, which can be an analogy to the consideration of electronic media through which I understand the Internet. The social sphere does not differ much from the same sphere for television or film. The so-called institutional sender that produces given software or hardware. In virtual 
reality, producer anonymity is often encountered, as in the case of game, software or messenger producers derive measurable benefits from introducing new solutions and curiosities to this world, which are often only in phase I (product launch) ${ }^{2}$ free and in terms of copyrights have the status of freeware. This problem concerns, as is the case in the real world, not only the technical parameters of the product, but also the appropriate promotion and creation of the brand from the product. Another aspect in this (social) sphere that can be realized practically only in the virtual dimension is the phenomenon called by Piotr Sitarski unfettered "collective authorship understood" (Sitarski, 2002) as collective programming of e.g. games. The final result is the work of many authors, often imperfect and completely devoid of any copyright. This is a typically author activity in which the user receives broadcasting prerogatives. It is not directly related to virtual reality, because if this were the case, the actual author would use interactivity to grant some limited rights to the user to navigate the program in a friendly way, and in this case it is only about creating software without any guidelines or restrictions. The social sphere described so far, which sees the sender in the context of the broadcasting instance, is strongly determined by market strategies, especially in the stages of introduction, growth and maturity of a technical product $^{3}$.

A more important sphere for considering this dissertation is the sphere covering the sender of the work within the meaning of authorship. This issue in virtual reality raises several doubts. The first problem is the inability to make an error-free statement of authorship, not only in the context of identity but individuality. Therefore, even in the case of participants of virtual reality, we can never be sure whether a person entering into communication relations with us is one person or many, and whether he is always the same or people. The second problem is the existence of the text. By communicating with the recipient, the sender creates a certain structure that is traditionally understood as text, however, in virtual reality the interpretation of this concept is not entirely incorrect, because it violates most of the rules assigned to the text and having no references in the new reality. The third and last problem about the sender in virtual reality is narrative. The questions of many researchers who are wondering if we can talk about such a phenomenon in this specific situation seem interesting. And here two issues arise in this regard. One concerns a technical issue and the other a social one. However, it is perceived differently than it was in the case of the holistic approach to the sender's case. The technical sphere concerns the broadcaster called by Piotr Sitarski a "great programmer" which is an analogy to the film broadcaster called a great image maker. These analogies do not end only with the similarity of words but embrace the whole essence of these broadcasters. In the case of virtual reality and the functioning of a "great programmer" in it, its task is to create the appearance and structure of the new world.

"The world can be shown (or rather: created) in different ways, some of which are closer to normal perception, others from it. On the one hand, we have visual ways of presenting the world, often extremely advanced, enabling three-dimensional vision, a rich palette of tactile sensations, spatial sound (...) On the other hand, we find pseudo-worlds very poor, office sets" (Sitarski, 2002).

\footnotetext{
${ }^{2}$ I use economic terminology in the field of so-called product life cycle.

${ }^{3}$ The product life cycle includes 4 phases: I - introduction, II - growth, III - maturity, IV - decline.
} 
The second mention of narrative in virtual reality concerns the social sphere based on interactivity, which, as I wrote above, is understood as the feedback of a system composed of the user and the system. It should be remembered that the author himself provides the recipient with a model of the world in which interaction is possible, especially when the sender is also a "great programmer". In relations, the public organization and the individual recipient comes to communication between its selected members. However, communication is not always a narrative and interaction does not always occur. As Ryszard Kluszczyński notes, "both these processes (...) do not occur at the same level" (Kluszczyński, 1996). Interaction does not always occur, especially when the participant only creates a vision of his idea without leaving it open to discussion. The case of no narrative is simply the lack of reaction from other participants, which may be a consequence of the lack of interaction, but does not have to.

The conclusion that comes to mind regarding the virtual sender is obvious and at the same time paradoxical. He is the creator of virtual reality, but at the same time, despite the communicative nature, he does not accept this entire process. Therefore, he is not entirely responsible for communication processes in virtual reality. It probably happens that some prerogatives, which in the real world are assigned only to him (the sender), are passed on to someone else - the recipient.

\section{VIRTUAL REALITY RECIPIENT / CLIENT}

When considering the problem of the recipient in virtual reality, Piotr Sitarski proposes to consider it from two perspectives: in-text and out-of-text. The first approach is discussed in detail by experts in audiovisual media, especially film. They are such researchers as: Peter H. Linday, Donald A. Norman, Selfridge - they believe that the recipient perceives the image to his pattern (this concept refers to the model of J. Locke's mind). In other words, the recipient must decide on the subject's compliance with the pattern. Selfridge proposed, among others, the concept of image recognition consisting in assigning certain images to the hierarchy, which was determined by the so-called "Human demons" (Sitarski, 2002, za Linday, Norman, 1984). In contrast, representatives of semiotic theories postulated the concept of the viewer decoding the message. This means reducing the recipient only to the code comprehension function. The uniqueness and uniqueness of the recipient were not taken into account in these theories, because they did not fit (or rather could interfere) with the decoding process. The next approach is pragmatism, where the

"recipient's competences are not limited in this approach to knowledge of the code or symbolic interaction, but include interpretive activity and interaction with the text. Therefore, not only the function of the recipient changes, but also its meaning" (Sitarski, 2002).

In other words, the text cannot exist without the recipient. Like the pragmatic approach, cognitive orientation is consumer-oriented. According to this concept, the recipient is received through a broadly understood narrative. This concept was modified by David Bordwell, who believed that the recipient understands the text by building the meanings 
that the text provides it. The last orientation presented is the "concept of pleasure"4 described by Roland Barthes and continued by John Fiske. They believe that the pleasure achieved by the recipient is a powerful force capable of directing the reading of the text in the direction desired for the recipient himself. Barthes himself distinguished several types of such pleasure, and Fiske came to the conclusion that the recipient's pleasure of receiving the text is not essentially solitary, but is always socially rooted in a smaller or larger group to which the recipient belongs. Therefore, it gives grounds to accept the statement that members of the environment formulating a social group around a selected social problem and joining this rather specific community derive pleasure from it, not individual, but collective. Thus, unknowingly, it is part of the creation of culture in this mass environment. Attempting to assume in virtual reality that the recipient is only a passive viewer is completely wrong. It is undoubtedly active, which is manifested in the products of its activity. Wiesław Godzic also draws interesting conclusions in his work Watching and other pleasures of popular culture. The author, after analyzing the phenomenon of the recipient's activity, presents the actual ways of its implementation, more precisely the features acquired by the recipient of new media. First of all, it is socialization - Wiesław Godzic believes that the recipient is pro-social and seeks contact with others himself. Secondly, the pleasure of interactivity - "the viewer wants contact and communication - just as he wanted to identify with the characters of the film, camera or cinema institution" (Godzic, 1996). And thirdly, the control of meanings - it means not so much dominance over received meanings but becoming aware of their dominant role and its irreversibility and the inability to completely influence received meanings. However, this is not as pessimistic as it seems, although the text is a "cold" relay (Strykowski, 1997). This means that the virtual environment to avoid misunderstanding the message must be expressed very precisely, although deliberate manipulation of the message cannot be avoided in such a situation. In the concept of Godzica, the recipient ultimately determines the shape of the text, which at the same time decides absolutely about its interpretation. However, this is not entirely true, as it should be remembered that virtual reality is limited by software and hardware, which seriously reduces the number of possible paths for choosing the interpretation.

Returning to the beginning of the reflection on the recipient of virtual reality, there is still to be discussed the extra-textual issues of reception. The recipient in this perspective is considered in the context of the pros and cons of such participation. These considerations do not fall within the scope of the whole work, therefore I will only briefly focus on them and I will not comment on them. The main disadvantages of participation or rather the reception of virtual reality include the following accusations: dehumanization of

\footnotetext{
4 This is not a scientific term, because I have never encountered such in literature. This phenomenon is widely described in detail and does not have one accepted name. However, for the clarity and clarity of my work, I knocked myself to propose my own name for this phenomenon.

${ }^{5}$ Marshall McLuhan created the concept of "cold" and "warm" relays. The higher the number of information items in a given message, the hotter the message is, and vice versa - the colder it is, the fewer it provides the elements to decode its meaning. For example, a photographic and movie image is hot and a caricature is cold. This division is particularly important for educational processes, because the temperature of the message depends on the participation of recipients who must interpret this message, and thus perhaps also supplement the missing information elements. In the case of hot messages, the recipient's activity is poor, because most of the information is provided by the sender, while in the cold message the recipient must co-create this message to some extent, which is why it is more fully involved in the communication process (Strykowski, 1997).
} 
communication processes, alienation of users, restriction of freedom of choice through the limitations of computer programs and ultimately the narcotic effect of this medium. On the other hand, proponents of this way of perceiving the world include the advantages of this medium: the huge community potential of this environment, a good way of communication between people, the creation of new forms of human contact, the possibility of creating structures of grassroots democracy, the creation of social structures without any preconditions, the possibility of liberation from your own corporeality, i.e. choosing your own body, deciding on your own social image (Sitarski, 2002).

The above considerations proved how much the role of the sender and recipient in virtual reality is different and at the same time similar. It is impossible to say exactly where the creative role of the sender (author) ends and where the reception begins and how it is. New medium and new coding and decoding pathways induce researchers to intensively consider these phenomena.

\section{SOCIAL DIALOGUE AS THE BASIS FOR COMMUNICATION IN A VIRTUAL ORGANIZATION}

Communication in the network, according to observations, takes the form of social dialogue. This concept is related to public communication, usually institutional. Many interlocutors (messengers), most often referred to as social partners, participate in social dialogue. Dialogue in this sense has a broader meaning, as it includes not only conversation, but all activities that are to lead and bring about agreement. In other words, it is a social process based on partnership and mutual subjective treatment. Therefore, it differs from the "adjective" dialogue in terms of the number of interlocutors, the place and time of the conversation, the channel of communication, the situation and goals of communication, as well as the language of its messages. It should be remembered that in social dialogue the time relationship is not the same as the relationship in the dyadic situation (where interaction occurs at the same time for both participants). Because, as demonstrated above, social dialogue includes all activities aimed at reaching agreement, the duration of this dialogue cannot be limited.

According to Janina Fras, two aspects of social dialogue are the most important: ethicality and effectiveness.

"Ethical interpersonal communication is not only guided by specific principles but also willingness to defend them. Non-compliance with these rules is a clear violation of the ethics of communication" (Fras, 2001). Jürgen Habermas introduced the general principles of ethical communication by putting them in the form of a model whose essence is the coexistence of four ideas:

1. truthfulness (I'm talking about something, I'm telling the truth),

2. honesty (I really say what I think),

3. intelligibility (what I am saying is understandable for the partner),

4. the appropriateness of the interpersonal relationship between the sender and recipient (communication situation, the relationship between the participants of the dialogue is socially legalized; the sender maintains the right relationship between himself and the recipient of the message) (Habermas, 1988). 
In addition, Habermas introduced into his ethical communication model the need to meet two conditions:

- there must be a certain, even a minimum, common space in which all participants of the dialogue move in the same way (mutual understanding, common universe),

- participants in the dialogue must agree on the principles of explaining any words or statements incomprehensible to the partner (partners); there must be agreement as to the explanation of the words and the principles of these claims (Habermas, 1988).

As Janina Fras writes, "the flexibility of public communication (...) is today dominated by effectiveness, ad hoc and spectacular" (Fras, 2001). Which is also reflected in the online communities I research. By this I mean social dialogue in the meaning of Quintilian, which binds rhetoric and ethics and believes that a "participant of effective dialogue can be an honest, fluent person, i.e. vir bonus dicendi peritus". In addition, it is worth noting that the concept of social dialogue is one of the five basic concepts recognized as constitutional principles in the preamble to the Constitution of the Republic of Poland. Other principles are: "respect for freedom and justice, cooperation between authorities and the principle of subsidiarity". Thus, constitutional social dialogue is a dialogue in the sense of a sequence of conversations aimed at reaching agreement in a situation of conflict of positions and interests, while the dialogue of social partners is reaching agreement through talks (negotiations and negotiations). And so communication in partners in a virtual environment is understood as a dialogue of social partners in its negotiating aspect, where the subject of research are:

- tasks aimed at achieving victory for both parties,

- compromise behavior of the parties,

- seeking mutual interest of both parties,

- behaviors of empathizing with each other in their needs and feelings to find a solution,

- exchange of information that is spontaneous (by asking questions and making representations).

\section{HYPERTEXTUALITY OF SOCIAL DISCOURSE IN A VIRTUAL ORGANIZATION}

Most often, the participants of considerations about the phenomenon of virtual reality, which has an audiovisual character and allows a human being to be located inside an electronically designed space-time and actively participate in the events taking place in it, come to the conclusion that the relationship between man and machine is nothing but a communication situation devoid of traditional strong reference function and deeply violating the "old" Jacobson type of relationship between the sender of the message and the recipient. And it is this communication problem that is the most interesting for me today because it is the starting point for further media coverage, because it illustrates the scope and dimensions of the transformation that occurs under the pressure of technological pluralism not only in culture but also in many other areas of the modern world: the real and virtual. Communication activity in the new reality is combined with a way of structuring it in that space. The text is not linear as it is in the real world but has a spatial structure, fluid and completely dependent on the recipient and not the creator. In the real world there is talk of such a way of creating, and basically receiving the text as intertextuality. As an interpretative category, this concept initially appeared only on the basis of literary theory as 
a vision, and was introduced by J. Kristeva. The glossary of literary terms defines intertuality "as a sphere of inter-textual connections and references in which a given work participates, the area of expression and ways of speaking, in which it determines its form and meaning" (Sławiński, 1988). He mentions intertextuality:

- Relations between textual levels inside the work, idiolects of individual characters;

- Between the actual text and the metatext;

- Recall specific statements that precede the work, quotes, allusions, paraphrases;

- Imitation of forms and styles of expression, idiolects, dialects, sociolects, functional styles etc .;

- Belonging to a specific literary genre;

- Inter Intersemiotic references between word texts and texts representing other character systems (Sławiński, 1988).

When transferring textuality considerations to virtual reality, the existence of intetextuality is not questioned, however it is differently materialized. The awareness of the hyperlink on the web and the ability to distinguish it from the materialized traces of one text in another, which is a feature of interculturalism, allows us to call this phenomenon hypertextuality. Changing the prefix is not only related to the new environment, the new research space, but has structural features. The very use of the concept of hyperexuality is often associated with a terminological research problem consisting in determining the correctness in the use of the concept of text in the network and, as a result, hyperertextuality and the concept of message. It is believed that the concept of hyperertextuality is more correct than the concept of message, which is used to define one-way communication, because the conceptual scope of this term is determined in the context of process models related to the transmission of the coded signal and coding of the semantic content of a set of characters. Understanding, therefore, network communication as a text, is primarily a focus not so much on the transmission of meanings, but on its creation. From the perspective of literary theory, the unit of text is a lexis ${ }^{6}$ that has its reference also in hyperspace in the form of a hyperlink, which is found only in electronic text. In various fields of humanities, scientists are inclined to understand the text in new media not only as the creators of meanings but extend this understanding to all cultural creations. Since culture is a collection of texts, it

"is similarly a collection of lexis, relatively coherent and indivisible or divisible in the sense in which metalexia, i.e. it can simply be a collection of proper lexis (in the sense of systematics). (...) The fact will be every fact, every element that we can classify as an element of culture" (Mochola, 2019).

According to Roland Barthes, the lexis is a unit of reading, consisting of words, tasks or paragraphs a portion of meaning. In the electronic song, as Mariusz Pisarski notes,

"we are dealing with "personalization « of this gesture, and even its extortion, through a hyperlink. (...) In hypertext, the lexia is rather a unit of the text itself, it comes from a broadcasting instance, and may not coincide with reading units, although the more it does, the better" (Pisarski, 2019).

\footnotetext{
${ }^{6}$ Lexicon - is a relatively coherent and indivisible unit of text.
} 
Therefore, in the virtual space in Barthes' view, secondary structuring occurs, because there is no longer a homogeneous sequence of printed characters but variable test sequences on the screen follow. This extends the essential features of the text (Gwóźdź, 1992) ${ }^{7}$. The main change concerns the perception of the text as a dynamic mechanism of producing meanings, and not the static reception of the record as before. This is particularly important for the study of cultural products such as behavioral patterns, for example. A dynamic view of the text allows you to see not only the constant but also the variable form of the cultural product. Hypertextuality in the network

"is closely related to the hypertext mechanism, which is based on the creation of an internal system of links that would connect the places indicated in the text, similarly to encyclopedic journalists, but more efficiently and openly, i.e. allowing the reader to change these connections independently" (Sitarski, 2002).

The essential feature of hypertext is its non-linearity, however, it does not exclude the linearity of the text. This statement results from the fact that, after all, hypertext is a type of text, and more precisely, textuality rules over hypertext. Hence, hypertext can be a written word, picture, sound. Therefore, the study of network communication in such a broad sense of the text should not surprise or constitute any research obstacle. The second significant feature of hypertext is the large number of navigations. It is a finite number of connections but the connection paths are undefined. The lack of many means of expression and focusing solely on the text, as I have argued above, does not exclude the existence of hypertext, which is particularly visible with its other feature. There is an infinite number of navigation through the messages of participants, which causes the creation of new meanings, which keeps the specificity of network communication in the form of its hyper-reality and innovation in the production of new meanings. The hypertextual organization of network discourse gives us a chance to create more and more open works, which Umberto Eco writes about in his book Open Work. Form and indeterminacy of contemporary poetics (1994). He compares the logic of narrative activity on the web to dream logic. Dream logic optics refers more to a potential hypertext reader than it is an attempt to create such a way of organizing statements. As Andrzej R. Mochola writes, hypertext is (...) a response to the logic of dreams, not its realization. Contemporary attempts to create a theory describing the operation of hypertext while at the same time rendering its semantic context are still insufficient and this task is still open to researchers.

Operation through virtual reality raises many possibilities and difficulties. The environmental research issues outlined above only affect the personal environment (clients, recipients and personalized environment). Understanding the mechanisms of technical functioning and the human factor in this world can give real profits. Lack of humility towards this medium and disproportionate losses as to the cost of their own ignorance.

\section{REFERENCES}

Biocca, F. (1992). Communication Wtithin Vitrual Reality: Creating a Space for Researche. "Journal od Communication" No. 42/4.

\footnotetext{
7 There are four characteristics of a text: stability (a kind of fixed complex of characters), structurality (the text is the implementation of a certain sign system), expression (is the source of meanings), demarcation (it can be described as a unit of expression) (Gwóźdź, 1992).
} 
Fras, J. (2001). Dialog we współczesnym komunikowaniu publicznym [w:] Borkowski, I., Woźny, A., red., Nowe media. Nowe w mediach. Wrocław: Oficyna Wydawnicza Arboretum, s. 110 .

Godzic, W. (1996). Oglądanie i inne przyjemności kultury popularnej. Kraków: Universitas.

Gwóźdź, A. (1992). Kultura-komunikacja-film. O tekście filmowym. Kraków: Wydawnictwo Literackie.

Habermas, J. (1988). Teoria komunikowania. Boston: Beacon Press.

Hiem, M. (1993). Metaphysics of Virtual Reality. Oxford-New York: Oxford University Press. Kluszczyński, R.W. (1966). Interaktywność - wtaściwość odbioru czy nowa jakość sztuki/kultury [w:] Seidler-Janiszewska, A., red., Estetyczne przestrzenie wspótczesności. Warszawa: Instytut Kultury.

Kłeczek, J. (2015). Nielinearność narracji teatralnych a hipertekstualność obiektów nowych mediów [w:] Oleszek, B., Wiśniewska, M., red., Wspótczesny teatr i film wobec wyzwań nowych mediów. Toruń: Wydawnictwo UMK.

Krueger, M. (1991). Artificial Reality, Reading. Addison-Wesley: Mass.

Lalewicz, J. (1985). Socjologia komunikacji literackiej. Wrocław: Ossolineum.

Linday, P.H., Norman, D.A. (1984). Kowaliszyn A., tłum., Procesy przetwarzania informacji u człowieka. Warszawa: PWN.

Mochol, A.R. (2019). Szkice Hipertekstualne. Access on the internet: http://www.mochola. org/hypertext.

Pisarski, M. Access on the internet: http://pl.wikipedia.org/wiki/Hipertekst.

Reid, E. (1994). Cultural Formations in Text-Based Virtual Realities. Melbourne: Universtiy of Melbourne.

Sitarski, P. (2002). Rozmowa z cyfrowym cieniem. Model komunikacyjny rzeczywistości wirtualnej. Kraków: RABID.

Sławiński, J. (1988). Intertekstualność [w:] Głowiński, M. i in., red., Słownik terminów literackich. Wrocław: Wydawnictwo „Open”.

Tucker, R.N., red. (1989). Interactive Media. The Human Issues. London: Kogan Page.

Żmigrodzki, P. (2001). O intertekstualności dyskursu politycznego $w$ mediach (na przyktadzie rozmów z politykami) [w:] Borkowski, I. Woźny, A., red., Nowe media. Nowe w mediach. Wrocław: Oficyna Wydawnicza Arboretum.

DOI: $10.7862 /$ rz.2020.hss.3

The text was submitted to the editorial office: February 2020.

The text was accepted for publication: March 2020. 
